\title{
Needs-Based Health Care Funding: Implications for Resource Distribution in Ontario
}

\author{
Kelly Bedard \\ Department of Economics \\ Claremont McKenna College \\ Claremont, California \\ bedardk@benson.mckenna.edu \\ Allan W. Gregory \\ Department of Economics \\ Queen's University \\ Kingston, Ontario \\ awg@qed.econ.queensu.ca
}

\author{
John Dorland \\ Department of Community \\ Health and Epidemiology \\ Queen's University \\ Kingston, Ontario \\ dorlandj@post.queensu.ca \\ Joanne Roberts \\ Department of Economics \\ University of Toronto \\ Toronto, Ontario \\ jorob@chass.utoronto.ca
}

October, 1999

\begin{abstract}
Capitation models have been suggested as an alternative to funding methods based on historical utilization patterns. Capitation funding distributes resources to regions or programs according to their population, adjusted for the age and gender composition and relative need. The most commonly used relative needs measure is the Standardized Mortality Ratio (SMR). This paper compares the distribution of resources in Ontario implied by a variety of capitation formula. Another aspect of this research is to design a mechanism that translates the SMR into a funding allocation index. We specify a non-linear model to capture the relationship between current expenditures and the SMR while controlling for historical utilization factors. In contrast to previous work which has assumed a linear relationship between expenditures and need, our estimates suggest that the relationship may actually be highly non-linear. This non-linearity increases transfers to regions of relative need relative to a linear capitation program.
\end{abstract}

The authors thank the National Health Research and Development Program (NHRDP) for financial support. Bedard also thanks the Canadian International Labour Network (CILN) at McMaster University, and Roberts thanks the Social Science and Humanities Research Council of Canada for financial support. We thank John Burbidge, David Feeny, Paul Grootendorst, and four anonymous referees for helpful comments. We are grateful to D. O'Mahonie, P. Brenders, M. Zwyer, and S. Charbonneau at the Ontario Ministry of Health for providing us with data.

Keywords: Capitation Funding, Standardized Mortality Ratios, Region, Age, and Gender

JEL Classification: I0, H51 


\section{Introduction}

For publicly funded health care systems, rising costs and concerns about inequitable access have mounted public pressure to move toward 'fairer' health care funding systems. Although there has been much debate on what constitutes a 'fairer' system, capitation funding models are appealing to many people as an alternative to systems that allocate funds based on historical utilization patterns. The appeal of capitation models emanates from their attempt to reflect equitably the relative health care needs of different communities. More specifically, capitation models attempt to distribute resources across regions in direct proportion to their age and gender adjusted population size and other factors that might reflect relative need. ${ }^{1}$ Although these models have some intrinsic appeal, very little methodological research has been done on how to implement these models. Indeed little is known about the sensitivity of capitation models to changes in the key parameters that make up the relative needs indices.

In this paper, we compare the funding allocations under a variety of previously suggested and newly proposed capitation models for Ontario. In particular, we contrast funding allocations under per capita funding, age and gender adjusted transfers, and various needs-based adjusted funding mechanisms. Another contribution of this research is to develop a methodology for estimating the dollar value of relative need for each region by controlling for historical utilization factors in current expenditures while simultaneously respecting the balanced budget condition. All needs-based capitation models that we are aware of arbitrarily parameterize the needs-based components in the capitation funding model. For example, the capitation model employed in the United Kingdom uses the square root of the Standardized Mortality Ratio (SMR) and Birch and Eyles (1991) and Eyles, Birch, Chambers, Hurley, and Hutchinson (1991) advocate a straight SMR as a

\footnotetext{
1 Throughout this paper, we define 'need' as the capacity to benefit from health care. This issue of what constitutes need is an interesting one. A needs based program would like to re-allocate toward regions with a higher modifiable burden of illness. As pointed out by a referee, many measures of need make no distinction between whether or not morbidity is modifiable.
} 
measure of relative need. In contrast, by isolating the relative needs component in current expenditures, we attempt to estimate the functional relationship for the SMR to enter the funding formula. Carr-Hill et al (1993), Raftery (1993), Sheldon et al (1993), and Smith et al (1993) also attempt to disentangle the relationship between relative needs as reflected in the SMR and current expenditures. However these papers restrict this relationship to be linear.

Since Canadian health care is publicly funded, portable across provinces, and fairly comprehensive in its coverage, Ontario data provide an opportunity to construct needsbased health care budgets using the capitation methodology. Since most health care services are publicly funded, there are no direct financial costs which guarantees access (although of course good access involves low non-financial barriers as well). This implies that part of current expenditures at the regional level are more likely to reflect health care need than is the case under a more privately funded system. In a private health care system, the distribution of services depends heavily on the ability to pay for services. We attempt to isolate the needs-based components of current expenditures by controlling for historical utilization factors. Finally, although some pilot projects have been discussed and adopted on a small scale, Ontario has not implemented capitation funding on a wide scale. All of these factors suggest that Ontario is an excellent choice for this kind of study.

There are two principal findings with respect to capitation funding for the province of Ontario. First, we demonstrate the sensitivity of capitation funding allocations to model specification and the correspondingly large monetary transfers that can result from funding mechanism choice. Second, in contrast to previous work that has assumed a linear relation for the needs index, estimates obtained for Ontario data suggest the relationship is non-linear with much higher transfers to regions of relative need.

This study only considers capitation funding models in the context of a comprehensive universal publicly funded health care system under a fixed (given) budget. Many issues like risk selection as discussed for example in Newhouse (1996) may be less prevalent in 
an environment where insurance and health care provision are guaranteed. If capitation funding were to be applied by private insurers (e.g. a HMO) or on an income and age related basis (Medicare and Medicaid), many of these more strategic considerations would become important issues. Some of these issues in capitation funding have been discussed in Keeler, Carter, and Newhouse (1998), Dwyer et al (1995), and Mataganis and Glennerster (1994). We also do not consider the across-program allocations within regions, and in this way, we abstract from many efficiency issues to focus solely on issues of first-round regional allocative 'fairness'.

The paper is organized as follows. Section 2 provides a descriptive background outlining capitation funding and the most commonly used needs index, the Standard Mortality Ratio. Section 3 develops the more formal side of capitation and discusses an estimation approach for constructing a new capitation model. Section 4 details the data available for constructing capitation funding models and evaluates their quality. Section 5 summarizes core results for regional funding under needs-based funding using the Standardized Mortality Ratio (SMR) as a proxy for need. Section 6 considers the implications for the distribution of health care funding when health status measures are used in place of the SMR to reflect need. Section 7 concludes.

\section{Capitation Funding and Standardized Mortality Ratios}

The objective of capitation funding models for jurisdictions with publicly funded health care is to distribute the health budget among regions in a way that reflects the relative needs of the regions' population as opposed to their institutions or numbers of physicians. ${ }^{2}$ This focus suggests the simplest capitation model which distributes funds to health regions is on a per capita basis. This method, however, suffers from many shortcomings. Perhaps, the most obvious failing of this approach is its inability to account for differing health care requirements across age groups. For example, a region with a

2 For our empirical application with Ontario data, regions will correspond to counties. 
disproportionately elderly population will require more health care resources than a similar region with a relatively younger population. Generally, capitation models use age and gender adjusted populations rather than raw population counts in order to distribute more resources to regions with relatively more people in high need groups.

In practice, capitation models adjust for many factors beyond age and gender since there is wide-spread agreement among those advocating capitation that age and gender alone cannot adequately account for differing relative health care needs. In an ideal world, these 'need' adjustments would be made using prospective measures. Since such measures do not exist, capitation funding models must rely on retrospective indicators. Health status measures are often cited as appropriate measures of relative need. However, these measures cannot themselves be used in an on-going funding system due to data inavailability and potential manipulation by interested parties. To illustrate the manipulability of these measures, consider a funding system that re-allocated funds toward regions where people claimed to be sicker than average. In such a system, every region would have an incentive to misreport their relative health. Nevertheless, a good measure of need should not only guard against manipulation, but also be highly correlated with health status.

One commonly-used proxy for relative health care need is the Standardized Mortality Ratio (SMR). The SMR is a single index number which compares the mortality experience of a given region's population to the experience of a reference (or base) population. Since a capitation model operates under a balanced (fixed) budget, the allocation formula is constructed to address relative, rather than absolute need. Everything else being equal, regions with greater relative health care requirements (reflected by higher SMRs) are therefore allocated relatively more resources.

Although reliance on the SMR to adjust for regional needs has been criticized, it is nevertheless widely-used. ${ }^{3}$ The SMR is attractive because it is easily calculated, uses

3 See D'arcy and Siddique (1985), Carstairs and Morris (1989), and Bedard, Dorland, Gregory, and Rosenberg (1999). 
readily available data, and is difficult to manipulate. However, it has been argued that the SMR is sometimes a poor proxy for morbidity, since it is biased towards deaths in older age groups.

While there is an established literature looking at the relationship between SMRs, socio-economic factors, and health status (Hay (1988); Carstairs and Morris (1989a-c); Mays and Chinn (1989); Morris and Carstairs (1991); Birch, Eyles, and Newbold (1995); and Bedard, Dorland, Gregory, and Rosenberg (1999)), there are few published studies that consider the appropriate functional form for a funding relationship. For instance, if a region has a higher than average mortality rate, say $10 \%$ higher than average, exactly how many additional resources should be redistributed to this region, and given a balanced budget requirement, which regions should these funds be taken from? There are many ways to incorporate SMRs into a capitation funding model so that regions with relatively high SMRs receive more funds and still maintain a balanced budget. However, formulas that incorporate different SMR measures will imply different resource redistributions.

Although this issue has been virtually overlooked in the academic literature, it is fundamental to applications of capitation funding. For example, the United Kingdom capitation model initially used a simple linear SMR function in an attempt to distribute funding to regions with greater health care needs. However, practical considerations suggested that this resulted in too large a redistribution of funds, and therefore, the formula was modified to include the square root of the SMR in order to limit the re-allocation funds (Snaith (1978); and Raftery (1993)). Although such ad hoc reparameterizations succeed in limiting the transfer of funds to high mortality areas, they are difficult to justify and are inadequate for long-run needs-based planning.

It is important to keep in mind, however, that cross-border flows across counties might persist and mitigate the redistribution of services. Under the historical utilization system, funds are paid directly to service providers. This means that Toronto and several other large medical centers receive a larger proportion of funds, controlling for popula- 
tion, because they provide a disproportionately large number of services. Under a relative needs-based funding scheme, resources might initially be given to regions, but some regions might choose to refer patients requiring certain types of procedures to existing large medical centers. The actual redistribution of services will, therefore, depend on the present distribution of service recipients, and the subsequent decisions made by regional health authorities to encourage inter-regional referrals or to develop regionally based services. Of course, one cannot easily predict these 'second-round' expenditures, and this paper studies only the 'first-round' budget from a capitation funding model.

\section{Constructing Needs-Based Capitation Models}

The most basic capitation funding model is per capita funding. Under such a scheme, each county simply receives a share of the total budget that is directly proportional to its relative population size. Region $r^{\prime}$ s $(r=1, \ldots, R)$ budget $\left(B_{r}^{P C}\right)$ would then be given by

$$
B_{r}^{P C}=\frac{p o p_{r}}{p o p} B
$$

where $B$ is the provincial budget (assumed fixed). Since the shares sum to one, the funding scheme preserves a balanced budget.

An alternative capitation scheme would allocate funds based on age/gender adjusted population. Under an age and gender capitation funding model, a county's budget is determined by the number of individuals it has in each group and the provincial weight given for that group. More specifically, an age/gender adjustment weights the distribution of funds by the relative expenditures for the province on health care programs for each age/gender group. Health care programs include payments to hospitals, physicians, long term care and so on. One advantage of this approach is that it takes the distribution of different population groups across counties into account. An age/gender adjustment is especially important if the age/gender profiles differ substantially across counties. Not surprisingly, children under the age of 5 , women during child bearing years, and senior 
citizens require substantially more health care resources. ${ }^{4}$ The distribution of these age groups across counties will therefore be particularly important.

The age/gender adjusted budget is allocated across counties as follows. Denote the provincial average annual expenditures for a person of gender $g(g=1,2)$ and in age group $i(i=1, \ldots, I)$ on program $p(p=1, \ldots, P)$ by $\epsilon_{g i}^{p}$. Average publicly provided health care expenditures for a specified age/gender group member are then given by

$$
e_{g i}=\sum_{p} e_{g i}^{p}
$$

The age/gender adjusted allocation for region $r\left(B_{r}^{A G}\right)$ is then

$$
B_{r}^{A G}=\sum_{g} \sum_{i} e_{g i} p^{\text {pop }}{ }_{\text {rgi }},
$$

where pop rgi refers to the number of individuals in region $r$ with gender $g$ in age group $i .^{5}$ The age/gender adjusted budget also balances since by construction

$$
B=\sum_{r} B_{r}^{A G}
$$

In jurisdictions where capitation funding has been adopted, arguments have been made that age/gender adjustments alone are not adequate to reflect the distribution of need across counties. ${ }^{6}$ Typically, therefore, adjustments are made for relative need using other measures, the most common of which is the Standardized Mortality Ratio (SMR).

\footnotetext{
4 See Table A2 for a breakdown of expenditures on hospitals and physicians by age/gender group.

5 There is an interesting asymmetry in the capitation argument. To construct the $B_{r}^{A G}$ we need to calculate $e_{g i}$, the average expenditure for a specified age/gender group obtained from the sum of the same category across programs, $e_{g i}^{p}$. These calculations use historical utilization data. A valid question is, why are the current funds going to various age/gender categories 'fair' and could it not be the case that historical utilization patterns have over (or under) funded certain groups? We know of no strong argument against this view but would posit that advocates of capitation funding would suggest that the inequities within age/gender categories are small compared to the regional allocation disparities under historical utilization. While this issue is undoubtedly interesting, it is beyond the scope of the present study and we leave it as a topic for future research.

6 This is discussed in some detail in Hutchison et al(1999).
} 
A SMR compares the age/gender specific mortality rates for a given region to those of a base (reference) population. More precisely, the $S M R_{r}$ compares the number of actual deaths that occur in region $r$ to the number of deaths that would be expected if region $r$ experienced the same age/gender specific death rates as the base population. ${ }^{7}$ We define the SMR index as

$$
S M R_{r}=\frac{R R M R_{r}}{(1 / R) \sum_{r} R R M R_{r}}
$$

where $R R M R_{r}$ is the relative mortality rate of region $r$. This regional mortality rate $R R M R_{r}$ is

$$
R R M R_{r}=\frac{\sum_{g} \sum_{i} d_{r g i} \text { pop }_{r g i}}{\sum_{g} \sum_{i} d_{g i} \text { pop }_{r g i}}
$$

where the death rate, $d_{r g i}$, is defined as the number of deaths in a specific region/gender/ age group divided by the population of the specified group. The pop rgi term refers to all individuals of gender $g$ in age group $i$ in region $r$. The SMR divides the $R R M R_{r}$ by the mean $R R M R_{r}$ in order to standardize the index. As a result, the average SMR is 1. Regions with below average mortality rates have SMRs below 1, and those high mortality regions have SMRs above 1.

Since the SMR is often considered to be biased toward deaths in older populations, it is usually truncated using death rates of the population under the age of 65 or 75 (for example, see Carstairs and Morris 1989a-c). It is generally believed that using a truncated population produces an index which more adequately proxies health care need. Since the arguments in favor of one definition over another are not especially compelling, we consider the distributions resulting under each of these age cut-offs.

The simplest needs adjusted model uses a linear SMR adjustment that distributes the fixed budget $(B)$, across regions according to age/gender composition and relative need

\footnotetext{
7 See Birch, Eyles, and Newbold (1995) and Bedard, Dorland, Gregory, and Rosenberg (1999) for Canadian studies looking at the properties of SMRs and Carstairs and Morris (1989a-c) for British studies.
} 
(as measured by the SMR)

$$
B_{r}^{N}=\frac{S M R_{r} B_{r}^{A G}}{\sum_{r} S M R_{r} B_{r}^{A G}} B
$$

$B_{r}^{N}$ would then be the needs based budget for region $r$. The share allocated to region $r$ depends on population, age/gender composition, and relative need (SMR). Notice that if $S M R_{r}=1$ for all $r$ (age/gender specific mortality rates are identical across regions) then the regional budget is simply $B_{r}^{A G} .8$ We investigate regional redistributions relative to age-gender adjusted capitation for linear, square, and square root formulations of (3).

The primary concern with the needs-based funding scheme described by equation (3) is that there is no justification for this functional form. To our knowledge, all previous work has made ad hoc assumptions about the relationship between SMRs and resource need (linearity has usually been assumed), and there has been no attempt to estimate the appropriate relationship. We outline an approach that we hope makes some progress on this issue. Our goal is to allow the data to determine the functional relationship between need and the SMR by controlling for the historical utilization factors in current expenditures. This approach can also incorporate the need for centralization, program exclusion, and cost differences within a capitation framework.

Let $E_{r}$ denote current historical expenditures in region $r$ such that $B=\sum_{r} E_{r}=$ $\sum_{r} B_{r}^{N}$ given out fixed resource constraint. At this stage, it is important to distinguish between current historical expenditures in a region from the needs-based budget that will be allocated to that region. We further assume that the current expenditures $E_{r}$ is an additively separable function of the budget based on need $\left(B_{r}^{N}\right)$ and a component due to historical utilization patterns $\left(h u_{r}\right)$,

$$
E_{r}=\beta B_{r}^{N}+h u_{r}
$$

\footnotetext{
8 In general, the simple mechanism $B_{r}^{N}=S M R_{r} B^{A G}$ would fail to guarantee a balanced budget since in general $\sum_{r} S M R_{r} B_{r}^{A G} \neq B$. We normalize the allocation scheme in (3) to ensure that the budget balances.
} 
where $B_{r}^{N}$ has the following flexible form: $B_{r}^{N}=\frac{S M R_{r}^{\delta} E_{r}^{A G}}{\sum_{r} S M R_{r}^{\delta} E_{r}^{A G}} B^{N}$, where $E_{r}^{A G}$ represents the current expenditures age/gender adjusted in region $r$.

The manner in which the $S M R$ enters equation (4) is determined by $\delta$. For example, if $\delta=1$ the relation is linear and if $\delta=2$ the SMR enters quadratically. Intuitively, a high value of $\delta$ would result in larger transfers to regions with poor mortality experiences. Our approach is to estimate $\delta$ consistently by taking into account those factors determining the unobservable component $h u_{r}$ that captures historical utilization patterns. Relatively high values of $h u_{r}$ indicate a resource allocation in excess of what is warranted to meet relative need. We assume that historical utilization, $h u_{r}$, is an additive function of a vector of supply-side variables $\left(X_{r}\right)$ and an error term $\left(\nu_{r}\right)$, which is orthogonal to elements in $B_{r}^{N}$ and $X_{r}$,

$$
h u_{r}=X_{r} \alpha+\nu_{r}
$$

In this study, $X_{r}$ includes the number of physicians and specialists ${ }^{9}$ working in region $r$ and a constant. ${ }^{10}$ Other supply-side variables such as hospital beds, X-ray machines, clinics, laboratories, and so on could be included if such data were available. The non-linear estimating equation is given by

$$
E_{r}=\beta B_{r}^{N}+X_{r} \alpha+\nu_{r}
$$

The approach is to estimate the needs-based budget for region $r$ by controlling for historical utilization factors inherent in the current historical expenditure. Our ability to isolate the needs-based component depends critically on these supply side variables. Indeed if one did not include $X_{r}$ in (6), one would expect a 'low' $\delta$ estimate. This downward bias in the $\delta$ estimate reflects the fact that resources currently flow to regions with many hospitals and doctors and not necessarily to regions where relative need is greatest.

\footnotetext{
9 To clarify, 'physician' refers to general practitioners and 'specialist' refers to physician specialists.

10 We also ran all regressions including squared and cubed terms for physician and specialist counts. The regression results are not sensitive to the specification, so we report the simple formulation in equation $(5)$.
} 
If $B_{r}^{N}$ and $X_{r}$ are uncorrelated with $v_{r}$, the parameters of regression (6) can be consistently estimated using non-linear least squares. One might question the exogeneity of $B_{r}^{N}$ since higher current expenditures can be expected to lower current mortality so that $B_{r}^{N}$ is correlated with the error $v_{r}$. To investigate this issue, we estimate (6) by non-linear least squares (NLS) and non-linear instrumental variables (IV). For the IV estimation, lagged SMRs (1987 and 1988) and the square of the number of general practitioners and specialists are instruments. The lagged SMRs are highly correlated to current SMRs and yet there should be less reverse causation from current expenditures. We also test for the inconsistency of NLS estimation due to the possible endogeneity of the SMR. We calculate the non-linear variant of the Durbin-Wu-Hausman (DWH) statistic (see Davidson and MacKinnon, 1993). The null hypothesis of this test is the NLS estimates are consistent.

The other source of potential inconsistency is due to the correlation of the supply-side variables $X$ and the error in (6). Suppose physicians' location decisions are based on the size of the current regional health care budget, then there is feedback that would bias the NLS estimates. Moreover, it would be very difficult to find suitable variables to serve as instruments. In this case, very little could be identified, since all the relevant variables are jointly determined. Therefore, at this stage, we simply highlight this issue and say that the consistency of our estimates of (6) are conditional on the exogeneity assumption of $X$. However, in an implementation of our approach, we advise a careful consideration as to which supply-side variables be included.

\section{Data Issues for Needs-Based Funding}

All data are for Ontario during the late 1980s and the early 1990 s and are aggregated to the health district level which essentially correspond to counties, with the exception of the Metropolitan Toronto area which is amalgamated into a single region. For convenience, we therefore refer to the resulting 37 regions as counties (which are defined in Appendix 
A). ${ }^{11}$

Regional health districts are artificial constructs since there is no sense in which a health district currently serves only the needs of its population. Current expenditures at the health district level measures the expenditure in a particular region and not the residence of those who benefit from that expenditure. We would expect some cross-border activity as people from one region use facilities, or visit health care providers in another region. What capitation models do is to reallocate the funds in relation to the needs of the reference population. The question as to how or where these funds are spent is not addressed. One could easily imagine situations in which a region that received additional funds under capitation would turn around and purchase health services from the very region that 'lost' money. Moreover, once these capitation redistributions occur, regions could specialize in certain kinds of care and purchase other services from other regions. Capitation is concerned only with the gross flows of funds to a region.

Therefore, if we were to compare present funding at a district level to another allocation under some capitation model, we would be measuring slightly different things. Accordingly, we restrict attention to comparisons among the allocations implied by different capitation regimes.

A capitation funding model that adjusts for differences in relative need across both age/gender groups and regions requires a considerable amount of data. This includes data on health care expenditures, mortality, population, physician densities, and institutional locations. In particular, we require expenditure data for all major health care programs by region and estimated expenditures by age/gender group. County populations are broken down by gender and age. We generally use 5 year groups; however, we are forced to aggregate to 10 year age groups in some cases (this is indicated where relevant). The SMR calculations require population and mortality data by region, age and gender. Finally,

\footnotetext{
11 Of course, if these health districts were reorganized, the regional SMRs and the implied funding transfers would change. In particular, if one region were split into two, the new allocation of funding for the sub-regions would not, in general, sum to the previous allocation for that region.
} 
data on physician and specialist densities and institutional locations are needed to control for supply-side factors. The following sub-sections briefly describe the data used in this study and comment on its quality. A full description of all data and sources be can found in Appendix A.

Since one objective in this exercise is to extract the relationship between the SMR and need explained by current expenditures, we use both expenditure data and SMRs that have been averaged over our four year period. In doing this, we hope to smooth out any transitory fluctuations and to more accurately establish a relationship that could be used in funding allocations.

\section{Health Care Expenditures}

All health care expenditure data are from Ontario Health Expenditures: Analysis of Expenditures by Major Programs, Counties, and Health Districts ${ }^{12}$ (1989/90-1992/93) and are reported in real 1989 Canadian dollars. The expenditure data are summarized in Table A2 in Appendix A. This table includes the average annual expenditures (between $1989 / 90$ and $1992 / 93)$ as well as the percentage of spending allocated to the Ontario Health Insurance Plan (OHIP), hospitals, the Ontario Drug Benefit Plan (ODB), long-term care, and the residual (spending on programs that are not included on our major programs list).

The data required to obtain age/gender adjusted expenditures come directly from OHIP, ODB, the Hospital Division of the Ontario Ministry of Health, and the long-term care expenditures reported in Ontario Health Expenditures: Analysis of Expenditures by Major Programs, Counties, and Health Districts. ${ }^{13}$ The OHIP data are average age/gender annual expenditures estimated by the OHIP division of the Ontario Ministry of Health. The ODB data are age/gender average annual expenditures for elderly people and people residing in long-term care facilities. However, a portion of ODB expenditures are used by people on welfare. Since we did not have an age/gender breakdown for this portion

$1298 \%$ of the Ministry of Health's total expenditures are distributed into geographic areas on the basis of identifiable programs as defined in the Public Accounts of Ontario.

13 We thank the Ontario Ministry of Health for providing this data. 
of ODB expenditures, we allocated it on a per capita basis. This should not significantly alter the allocation due to the small share of expenditures that welfare cases represent. Hospital expenditures were proxied by using annual average resource-weighted hospital cases broken down by age/gender category. Long-term care expenditures were allocated on a per capita basis for people over the age of $65 .{ }^{14}$

Expenditures on these major programs constitute approximately $88 \%$ of total program spending. The remaining $12 \%$ of the health budget, for which we lack age/gender specific spending estimates, is allocated on a per capita basis. ${ }^{15}$ Refer to Appendix A for a detailed description of the variables used to calculate age/gender adjusted expenditures.

\section{Relative Need Measures}

The SMR calculation requires population and mortality data by age, gender, and county. We use mortality data from 1989-93 and population counts for 1991. All data are standardized to the Ontario county definitions and are further broken into five year age groups by gender (there are 28 age/gender groups). ${ }^{16}$ It would, of course, be preferable to use annual population figures, but these are unavailable.

In addition to the SMR, we wish to compare funding allocations under several more direct measures of health status. The health status measures we use include self-assessed health status, the health utility index (HUI3), general satisfaction with one's health, general freedom from pain, and the ability to see and remember. All indices are constructed using Ontario Health Survey data. A complete description of all health status variables is presented in Appendix A.

\footnotetext{
14 The expenditure data are discussed in greater detail in the data appendix.

15 Of course, if data were available, age/gender adjustments could be made for all funding.

16 All mortality data are from the Ontario Ministry of Health. Deaths are supposed to be assigned by place of residence, however, it is likely that there is some mis-reporting. This problem is likely most acute for elderly persons in long-term care outside of their county of residence, and it may not be such a problem since we exclude people over the age of 74 .
} 


\section{Supply-Side Variables}

Our intention is to measure relative need in a funding formula by controlling for supply-side (historical) factors such as physician densities and pre-existing institutional locations. Regional physician counts for specialists and general practitioners are from two publications Physician Manpower in Ontario (1989) and Physicians in Ontario (1992 and 1993). Since there is no source (published or otherwise) for physician data in 1990 and 1991, we linearly interpolate between 1989 and 1992. Given that physician counts tend to rise or fall slowly, this procedure is probably not too far off. Table A2 lists the average number of general practitioners and specialists between 1989 and 1993 by county.

\section{County Budgets under Needs-Based Funding}

In all budgetary comparisons, we use the age-gender adjusted allocation as our benchmark case. Column 1 in Table 1 presents the county funding levels implied by the agegender adjusted capitation (equation (2)). The difference between per capita funding and age/gender adjusted funding is that the latter takes the relative costs associated with each age/gender group into account. Table A2 lists the total population, as well as the percentage of the population under age 5 , over age 64 and female between 15 and 44 . Population counts are presented for these groups because they are relatively heavy health care users. For example, in 1991 the average per person expenditures on OHIP and hospitals were $\$ 530$ and $\$ 739$ respectively. But, these averages are dominated by expenditures on the elderly. In 1991, Ontario spent $\$ 2753$ on hospital costs and $\$ 1024$ on payments to OHIP for the average senior citizen (aged greater than 64). ${ }^{17}$ Excluding senior citizens, the average per capita expenditures were $\$ 464$ for OHIP and $\$ 470$ on hospitals, with the average child under the age of five requiring $\$ 404$ and $\$ 722$ for OHIP and hospitals and women between the ages of 15 and 44 requiring an average of $\$ 607$ and $\$ 528$. While the proportion of women of child-bearing age and children under age 5 is fairly constant across counties, the

\footnotetext{
17 Expenditures on the elderly are considerably higher once ODB and long-term care costs are included.
} 
percent of the population made up of senior citizens differs substantially. Individuals over the age of 64 constitute less than $7 \%$ of the population in Peel and York Regions as opposed to approximately $16.5 \%$ of the population of Haliburton, Huron, and Muskoka. Given the relative health care expenditures on the elderly, and their uneven distribution across the province, it is not surprising that moving from a straight per capita resource distribution to an age/gender adjusted distribution would impact regions with disproportionately elderly populations.

Column 2 in Table 1 reports the percent change implied by moving from an age/gender adjusted allocation to a straight per capita allocation (equation (1)). It is easy to see that straight capitation implies a substantial redistribution from the allocation under the age/gender adjustment. For example, Muskoka's allocation under per capita would be $-12.32 \%$ relative to an age/gender adjusted distribution. On the other hand, Peel's allocation would increase $+18.9 \%$ when straight per capitation is used instead of the age/gender adjustment.

Column 3 in Table 1 presents the percent change in county level funding that would result under a simple linear SMR adjustment (equation (3)). Although the resulting funding allocations are somewhat similar to the per capita and age/gender adjusted allocations, there are some important differences. First, many northern, or at least less urban, counties with high death rates (SMRs by county are listed in Table A4) would receive more funding under a linear SMR model than under either per capita funding or age/gender adjusted funding. For instance, Cochrane, Kent, Northwestern, North Bay, Sudbury, and Timiskaming would all receive at least $20 \%$ greater funding increases under a simple linear SMR scheme than under a straight age/gender adjustment. Second, non-northern counties with large elderly populations (especially over 74) receive fewer funds under the linear SMR methodology than under the age/gender adjustment since the death rate of individuals over the age of 74 does not enter the SMR formula. This effect is reinforced if the SMR was restricted to individuals under the age of 65 . We return to this issue later 
in this section.

For comparative purposes, columns 4 and 5 presents the distribution of health care funds using the square root of the SMR and the squared SMR. That is, we replace SMR by $\mathrm{SMR}^{\frac{1}{2}}$ and $\mathrm{SMR}^{2}$ in equation (3), which preserves a balanced budget. Note that the allocations under the $\mathrm{SMR}^{\frac{1}{2}}\left(\mathrm{SMR}^{2}\right)$ funding model are smaller (higher) for high mortality regions, but lower (higher) for low mortality regions. In this way, replacing the SMR with $\mathrm{SMR}^{\frac{1}{2}}$ reduces the redistribution of funds to relatively high need areas and the use of $\mathrm{SMR}^{2}$ increases the flow of funds to high need areas. Sudbury, with a SMR of 1.15 for an age 75 cut-off $\left(\mathrm{SMR}_{<75}\right)$, and Huron, with a $\mathrm{SMR}_{<75}$ of 0.86 , offer a good comparison. The percentage change relative to age-gender capitation in the funds allocated to Sudbury are $+21.27,+10.28$, and +45.37 compared to $-9.46,-4.71$, and -18.96 for Huron under a straight $\mathrm{SMR}$, a $\mathrm{SMR}^{\frac{1}{2}}$, and a $\mathrm{SMR}^{2}$ adjustment respectively.

Table 2 presents the non-linear least squares (NLS) and non-linear instrumental variables (IV) regression results for equation (6) for the age 75 and 65 cut-offs. For the most part, the NLS and IV estimates are quite similar (with some departures for the results based on the 65 cut-off). The hypothesis tests that the NLS estimates are consistent (against an alternative of inconsistent due to the endogeneity SMR) using the Durbin-WuHausman test (labelled $F(2,30)$ for DWH) are easily retained at conventional levels for both age cut-offs.

Since we have only 37 observations, there is some concern about the finite sample properties of the NLS estimates and the DWH test statistic. Under the assumption of independently and identically distributed errors, we bootstrap (999 bootstrap replications) from the NLS residuals for the case with the 75 age cut-off from Table 2. This bootstrap also imposes the null hypothesis for the DWH test that the SMR is exogenous. In Figure 1, we graph the kernel density estimates (using a normal kernel) for each of the coefficients in equation (6). Superimposed on these are the normal distributions obtained from the mean and standard deviation of the bootstrap simulation. The distributions of the NLS 
estimates appear to be quite 'close' to normal and relatively precise. Also, the approximate p-value for the DWH test in Table 2 is 0.41 compared to the nominal value of 0.50 . In light of these findings, we concentrate only on the simpler non-linear least squares estimates.

There are several regularities. First, the estimated coefficient $(\delta)$ is substantially greater than unity and statistically significant at conventional levels in all cases. Secondly, $\delta$ is much larger when $\mathrm{SMR}_{<75}$ is used than when $\mathrm{SMR}_{<65}$ is used. Thirdly, the estimated $\delta$ is much smaller when physician and specialist densities are excluded. In the absence of these control variables, the estimated $\delta$ is 1.61 when the age cut-off is 75 and 1.35 when the age cut-off is 65 . This clearly illustrates the importance of conditioning on the supply-side variables.

The estimates from equation (6) give the total county level allocations. The percent change in health care allocations under this methodology compared to the age/gender adjusted budget are presented in Table 3 (for both $\mathrm{SMR}_{<75}$ and $\mathrm{SMR}_{<65}$ ). The allocations presented in Table 3 differ substantially from those presented in Table 1. If the SMR is restricted to individuals under the age of 75 , the redistribution of resources is more than $100 \%$ higher in some counties compared to a straight age/gender adjustment. This may serve as a partial explanation why those favoring capitation funding advocate a needsbased factor. Generally speaking, large northern counties would experience a substantial inflow of funds under a non-linear SMR adjustment relative to either an age/gender adjustment or a linear SMR adjustment, while the opposite would be true for less urban, but more southern counties.

While the patterns are similar when the SMR is restricted to individuals under the age of 65 , the magnitude of redistribution is significantly diminished. For example, Metropoli$\tan$ Toronto would experience a $13.59 \%$ decrease in funding with a $\mathrm{SMR}_{<75}$ allocation, compared to $0.35 \%$ increase using a $\mathrm{SMR}_{<65}$. 


\section{County Budgets with Alternative Health Status Measures}

Following the literature, we consider some other measures that can be used as indicators of need. In particular, we consider both the self-assessed health status index (used by Birch, Eyles, and Newbold, 1995) and the Health Utility Index (discussed in Feeny et al, 1996 and Furlong et al, 1998) as measures of health status. ${ }^{18}$ For comparative purposes, we also consider several other health status measures contained in the Ontario Health Survey. These include general freedom from pain, satisfaction with one's health, the ability to remember, and the ability to see. ${ }^{19}$ Although such measures could not be used in an on-going index due to data inavailability and potential manipulation by interested parties, a 'good' needs-based measure should to be highly correlated with these health status measures. Table 4 presents the correlation between these health status indices and the SMR under both 75 and 65 year age cut-offs. The correlation between the SMR and the health status indices ranges from about 0.2 to 0.6 in absolute value. ${ }^{20}$ Importantly, the correlations with these health status measures are virtually unaffected when $\mathrm{SMR}^{\delta}$ is used (for any reasonable value of $\delta$ ).

While health status measures could not themselves be used in a health care funding model on an on-going basis, it is interesting to estimate the resource redistribution associated with replacing the SMR by morbidity based measures of need. ${ }^{21}$ We present the percent change in funds allocated to counties under all previously mentioned health status measures in Table 5. This table also presents the parameter estimates for $\beta$ and $\delta$ obtained from estimating equation (6) by NLS, using the health status measures in place of the $\mathrm{SMR}_{<75}$.

Several things are apparent. First, the allocations depend heavily on which of these

\footnotetext{
18 The HUI measure contains information on health status that is weighted by information on preferences 19 Note that vision, cognition, and pain functional measures are components of the health utility index. 20 The correlation between health status measures varies somewhat more, ranging from 0.02 to 0.7 .

21 Although most of these measures have never been suggested for use as indicators of need in capitation programs, these results underline again the importance of model specification and parameter choice.
} 
measures is used. For example, the change in funds allocated to York Region range from $-50.96 \%$ using the general satisfaction with one's health index to $+16.06 \%$ using the ability to remember index. In fact, the direction of the allocation change is the same under all health status indices for only two counties.Comparing the results presented in Tables 3 and 5 for Metropolitan Toronto highlights the sensitivity of regional funding to the selection of the need measure used in a capitation funding model. In contrast to the estimates presented in previous tables, Metropolitan Toronto would experience a large inflow of funds if the self-reported health status or health satisfaction measure is used to measure relative need. These differences are even more dramatic in some other counties.

\section{Discussion}

Inevitably, moving from a historical utilization based health care funding system to a capitation based regional allocation system would entail some redistribution of funds. Surprising, and much more concerning, is our finding that relatively small capitation model specification and definitional changes lead to large regional funding re-allocations relative to other specification choices. The fact that there are large re-allocations poses a non-trivial problem for policymakers, since it makes choosing an 'appropriate' or 'fair' capitation system extremely difficult. While all discussion of changing funding systems is motivated by a concern for 'fairness', it is unclear what system best achieves these objectives, and even more unclear which capitation model reflects a just allocation.

Our empirical findings highlight the resource allocation differences implied by per capita, age/gender, linear SMR, and non-linear SMR adjusted capitation funding, but provide very little guidance for selecting one model over another. In addition to model selection, policymakers must also choose the cut-off for the SMR (we considered 65 or 75 years), programs to be excluded from the capitation formula, and the time period over which the SMR is averaged. Each of these choices also has non-trivial budgetary implications. Given the excessive sensitivity of re-allocations to perturbations and the 
absence of a concrete justification for choosing a specific form of capitation model, we conclude that much more quantitative analysis is required to justify their implementation for Ontario. Interestingly, more pilot projects of capitation have recently been announced for Ontario. 


\section{References}

Bedard, K., J. Dorland, A.W. Gregory, and M. Rosenberg (1999) "Standardized Mortality Ratios in Capitation Funding Models: Empirical Issues from Canadian Data." Canadian Public Policy, 25(1), 47-64

Birch, S., S. Chambers, J. Eyles, J. Hurley, and B. Hutchison (1990) "Development and Application of a Needs-Based Methodology for Allocating, Health Care Resources Among Populations at the County Level." CHEPA working paper, 90-13

Birch, S. and J. Eyles (1991) "Needs-Based Planning of Health Care: A Critical Appraisal of the Literature." CHEPA working paper, 91-5

Birch, S., J. Eyles, and K.B. Newbold (1995) “The Inevitability of Mortality? Evaluating Alternatives to the SMR." CHEPA working paper, 95-10

British Columbia Ministry of Health (1996) "Regional Funding Formula: A Resource Allocation Initiative to Support the Regionalization of Health Care Services."

Carr-Hill, R. and T. Sheldon (1992) "Rationality and the Use of Formulae in the Allocation of Resources to Health Care." Journal of Public Health Medicine, 14(2): 117-126

Carr-Hill, R., Sheldon, T., Smith, P., Martin, S., Peacock, S., and G. Hardman (1993) "Allocating Resources to Health Authorities: Development of a Method for Small Area Analysis of Use of Inpatient Services." British Medical Journal, 307: 1046-1049

Carstairs, V. and R. Morris (1989a) "Deprivation: Explaining Differences in Mortality Between Scotland and England and Wales." British Medical Journal, 299: 886-889

Carstairs, V. and R. Morris (1989b) "Deprivation and Mortality: an Alternative to Social Class?" Community Medicine, 11(3): 210-219

Carstairs, V. and R. Morris (1989c) "Deprivation, Mortality, and Resource Allocation." 
Community Medicine, 11(4): 364-372

Davidson, R. and J. MacKinnon (1993) Estimation and Inference in Econometrics, (New York: Oxford University Press)

D'Arcy, C. and C.M. Siddique (1985) "Unemployment and Health: An Analysis of Canada Health Survey Data." International Journal of Health Services, 15(4): 609-635

Driver, D. (1994) "Saskatchewan First to Implement New Funding Formula." Medical Post, May

Dwyer, D.S., Mitchell, O.S., Cole, R. and S.K. Reed (1995) "Evaluating Mental Health Capitation Treatment: Lessons from Panel Data." NBER Working Paper, 5297

Eyles, J. and S. Birch (1993) "A Population Needs-Based Approach to Health Care Resource Allocation and Planning in Ontario: A Link between Policy Goals and Practice?" Canadian Journal of Public Health, 84(2): 112-117

Eyles, J., S. Birch, S. Chambers, J. Hurley and B. Hutchinson (1991) "A Needs-Based Methodology for Allocating Health Care Resources in Ontario, Canada." Social Science and Medicine, 33(4) 489-500

Feeny, D., W. Furlong, M. Boyle, and G.W. Torrance (1995) "Multi-Attribute Health Status Classification Systems: Health Utilities Index." PharmacoEconomics, 7(6): $490-502$

Feeny, D., G.W. Torrance, and W..J. Furlong (1996) "Health Utilities Index." In Quality of Life and Pharmacoeconomics in Clinical Trials, ed. B. Spilker, (Philadelphia: Lippincott-Raven Publishers)

Furlong, W., D. Feeny, G.W. Torrance, C.H. Goldsmith, S. DePauw, Z. Zhu, M. Denton, and M. Boyle (1998) "Multiplicative Multi-Attribute Utility Function for the Health Utilities Index Mark 3 (HUI3) System: A Technical Report." CHEPA Working Paper 
$98-11$

Gilbert, R. et al. (1992) "The New South Wales Resource Allocation Formula: A Method for Equitable Health Funding." Australian Health Review, 15(1): 6-21

Hay, D.I. (1988) "Socioeconomic Status and Health Status: a Study of Males in the Canada Health Survey." Social Science and Medicine, 27(12): 1317-1325

Health Reforms Directorate (1992) "Population-Based Funding of Regional Health Authorities for the Purchase of Core Personal Health Services." New Zealand Ministry of Health, November

Health Services Funding Advisory Committee (1996) "Funding Regional Health Services in Alberta." Alberta Ministry of Health

Hutchison, B., J. Hurley, R. Reid, J. Dorland, S. Birch, M. Giacomini, and G. Pizzoferrato (1999) Capitation Formulation for Integrated Health Systems: A Policy Synthesis Canadian Health Services Research Foundation

Jamsen, R. (1994) "Planning and Financing System for Social and Health Services." Ministry of Social Affairs and Health, Helsinki, Finland, March

Keeler, E.B, G. Carter, and J.P. Newhouse (1998) "A Model of the Impact of Reimbursement Schemes on Health Care Choice." Journal of Health Economics, 17(3): 297-320

Manitoba Center for Health Policy and Evaluation (1996) "Needs-Based Planning for Manitoba's Generalist Physicians." Department of Community Health Sciences, Faculty of Medicine, University of Manitoba

Matsaganis, M., and H. Glennerster (1994) "The Threat of 'Cream Skimming' in the Post-reform NHS" Journal of Health Economics, 13(1): 31-60

Mays, N. and S. Chinn (1989) "Relation between All Cause Standardized Mortality Ratios 
and Two Indices of Deprivation at Regional and District Levels in England." Journal of Epidemiology and Community Health, 43: 191-199

Morris, R. and V. Carstairs (1991) "Which Deprivation? A Comparison of Selected Deprivation Indices." Community Medicine, 13(4): 318-326

Newhouse, J.P. (1996) "Reimbursing Health Plans and Health Providers: Efficiency in Production versus Selection." Journal of Economic Literature, 34: 1236-1263

Ontario Ministry of Health, Ministry of Community and Social Services, and Ministry of Citizenship (1993a) "Building Partnerships in Long-Term Care: A New Way to Plan, Manage, and Deliver Services and Community Support - A Local Planning Framework." May

Ontario Ministry of Health, Ministry of Community and Social Services, and Ministry of Citizenship (1993b) "Building Partnerships in Long-Term Care: A New Way to Plan, Manage, and Deliver Services and Community Support - A Policy Framework." April

Raftery, J. (1993) "Capitation Funding: Population, Age and Mortality Adjustments for Regional and District Health Authorities in England." British Medical Journal, 307: $1121-1124$

Saskatchewan Health (1996) "Introduction of Needs-Based Allocation of Resources to Saskatchewan Boards."

Services Development and Planning Branch, Operations Division (1993) "A Resource Allocation Formula for the New South Wales Health System - 1993 Revision." New South Wales (NSW) Department of Health, July

Sheldon, T. and R. Carr-Hill (1992) "Resource Allocation by Regression in the National Health Service: A Critique of the Resource Allocation Working Party's Review." Journal of the Royal Statistical Society, 155(3): 403-420 
Sheldon, T., Trevor, A., Smith, P., Borowitz, M., Martin, S., and R. Carr-Hill (1993) "Attempt at Deriving a Formula for Setting General Practitioner Fundholding Budgets." British Medical Journal, 307: 1059-1064

Smith, P., Sheldon, T., Trevor, A. Carr-Hill, R., Martin, S., and S. Peacock (1993) "Allocating Resources to Health Authorities: Results and Policy Implications of Small Area Analysis of Use of Inpatient Services." British Medical Journal, 307: 1050-1054

Snaith, A.H. (1978) "Subregional Resource Allocations in the National Health Service." Journal of Epidemiology and Community Health, 32: 16-21

Strategic Programs Branch (1994) "Introduction of Needs Based Allocation of Resources to Saskatchewan District Health Boards for 1994-95." Strategic Programs Branch, Saskatchewan Health, March

Torrance, G.W. (1986) "Measurement of Health State Utilities for Economic Appraisal: A Review." Journal of Health Economics, 5: 1-30

Torrance, G.W., D.H. Feeny, W.J. Furlong, R.D. Barr, Y. Zhang, and Q. Wang (1996) "Multi-Attribute Utility Function for a Comprehensive Health Status Classification System: Health Utilities Index Mark 2." Medical Care, 34(7): 702-722

Torrance, G.W., W. Furlong, D. Feeny, and M. Boyle. (1995) "Multi-Attribute Preference Functions." PharmacoEconomics, 7(6): 503-520 


\section{Appendix A: Data}

\section{A1. Health Care Expenditures}

\section{A1.1. Program Expenditures}

All health care expenditure data are from the Ontario Health Expenditures: Analysis of Expenditures by Major Programs, Counties, and Health Districts (1989/90-1992/93) and are reported in real 1989 Canadian dollars (deflated using the 1989 based CPI). This document provides data on expenditures at the county level. We use total expenditures and expenditures on the following major programs: hospitals, payments to physicians made by the Ontario Health Insurance Plan (OHIP), long-term care, and payments made by the Ontario Drug Benefit Plan (ODB). Residual expenditures are then calculated as the difference between total expenditures and expenditures on the major programs listed above. Table A1 summarizes average county level expenditures from 1989-92.

\section{A1.2. Age-Gender Adjusted Expenditures}

The data required to calculate age/gender adjusted expenditures was acquired directly from OHIP, ODB, the Hospital Division of the Ontario Ministry of Health and Ontario Health Expenditures: Analysis of Expenditures by Major Programs, Counties, and Health Districts (1989/90-1992/93). The age groups provided were 0-4, 5-9, 10-14, 15-24, 25-34, 35-44, 45-54, 55-64, 65-74, and 75+. OHIP produces annual expenditure estimates by age/gender group for physician payments. ODB also produces annual age/gender group expenditure estimates, however, expenditures are targeted at two populations: people over the age of 65 , and people on social assistance. The standard age/gender adjustment was undertaken for the first group. Unfortunately, we were unable to obtain age/gender expenditure estimates for the proportion of ODB expenditures going to individuals on social assistance. We, therefore, allocated this portion of the budget on a per capita basis. Since ODB expenditures on social assistance recipients is small, this does not have a significant impact on any results presented in this paper. The Hospital Division produces annual 
estimates of resource weighted hospital cases by age/gender group $\left(r w_{g i}\right)$. The estimated resource weighted hospital cases can then be used to estimate hospital expenditures by age/gender group in the following way:

$$
e_{g i}^{h}=\frac{r w_{g i} p o p_{g i}}{\sum_{g}^{2} \sum_{i}^{I} r w_{g i} p o p_{i g}} B^{h} .
$$

where $B^{h}$ is the total health care expenditures allocated to hospitals for the province. Finally, since long-term care (including home care) expenditures are primarily directed to people over the age of 65 , we allocate total long-term care expenditures on a per capita basis for that population sub-group.

While Hospital and OHIP age/gender estimates and Long-Term Care data exist for each year from 1989/90 through 1992/93, ODB estimates are only available for 1991/92 and $1992 / 93$. We, therefore, use the average for these two years to approximate the ODB data for $1989 / 90$ and $1990 / 91$.

\section{A3. Health Status Measures}

All health status measures, including self-assessed health status, the health utility index, general freedom from pain, and the ability to see and remember, are from form 5 of the Ontario Health Survey (OHS). There were approximately 44,000 respondents to this portion of the OHS. Health status variables (except for the health utility index) are categorical, with good health or freedom from the specified affliction scoring 0 and reported poor health or the existence of the specified affliction scoring 1 . The HUI3 is a score ranging from 0 to 1 where a low score indicates low utility. All variables are converted into relative indices using the same construction as the SMR calculation. A region with relatively low health status will thus have an index above 1 and a relatively healthy population will have an index below 1. The only exception is the HUI3 which moves in the opposite direction.

\section{A3.1. Self-Assessed Health Status}

Self-assessed health status, $S A H S$, is constructed by asking survey respondents to rate their health compared to people their age on a scale from 1 (excellent) to 5 (poor). 
The frequency of empty cells necessitates aggregation. We aggregate to two categories: 1-2 (excellent-very good) and 3-5 (good-poor). The results are not sensitive to this definition, we also ran all regressions defining the groups as $1-3$ and $4-5$, and the differences are always negligible. Since some age cells have very few observations, we use 10 year age categories instead of the 5 year age categories used in the SMR calculations. Our results are not sensitive to this definition, all regression results are largely unchanged when 5 or 15 year age categories are used. Finally, there is no $S A H S$ variable for people under 15 years of age, so children are excluded from this index.

\section{A3.2. Ability to See Measure}

The ability to see measure, $S E E$, is a yes $(0)$ or no (1) response to the question: Are you usually able to see well enough to read ordinary newsprint without glasses or contact lenses?

\section{A3.3. Ability to Remember Measure}

The ability to remember measure, $M E M$, is a response of good $(0)$ or less than good (1) to: How would you describe your usual ability to remember things? The four categories of answers provided to this question were collapsed into two. A person's ability to remember is defined as good if they reported usually being able to remember and as less than good if they reported that they were somewhat forgetful, very forgetful, or unable to remember anything at all. Our results, for this measure, as well as the freedom from pain and health satisfaction measures, are not sensitive to our aggregation.

\section{A3.4. Freedom from Pain Measure}

The freedom from pain measure, $P A I N$, is defined as pain free $(0)$ if the person reported either no pain or discomfort or pain and discomfort that is restricted to few activities and less than pain free (1) if the person responded that pain and discomfort prevents some or all activities. 


\section{A3.5. Health Satisfaction}

Personal satisfaction with health, $S A T$, is 0 if the person reported being somewhat or very satisfied with their health and 1 if they reported being not too satisfied or unsatisfied.

\section{A3.6. Health Utilities Index}

The Health Utilities Index (HUI3) is a composite measure of eight health attributes: vision, hearing, speech, ambulation, dexterity, emotion, cognition, and pain. These measures jointly identify 972,000 possible health states. The HUI3 then estimates and weighs health status outcomes in terms of preference measurements attained from a sample of 504 adults in Hamilton, Ontario. The HUI3 assigns an utility value of 1 to the highest health state for each component measure. The lower health states are correspondingly given estimated preference levels of less than 1 . The HUI3 assigns a value to each health state which is given by

$$
u=1.371\left(b_{1} * b_{2} * b_{3} * b_{4} * b_{5} * b_{6} * b_{7} * b_{8}\right)-0.371
$$

where $b_{i}$ denotes the utility value associated with the $i$ th health measure. The construction of this index is outlined in Feeny et al. (1996) and Furlong et al. (1998). 

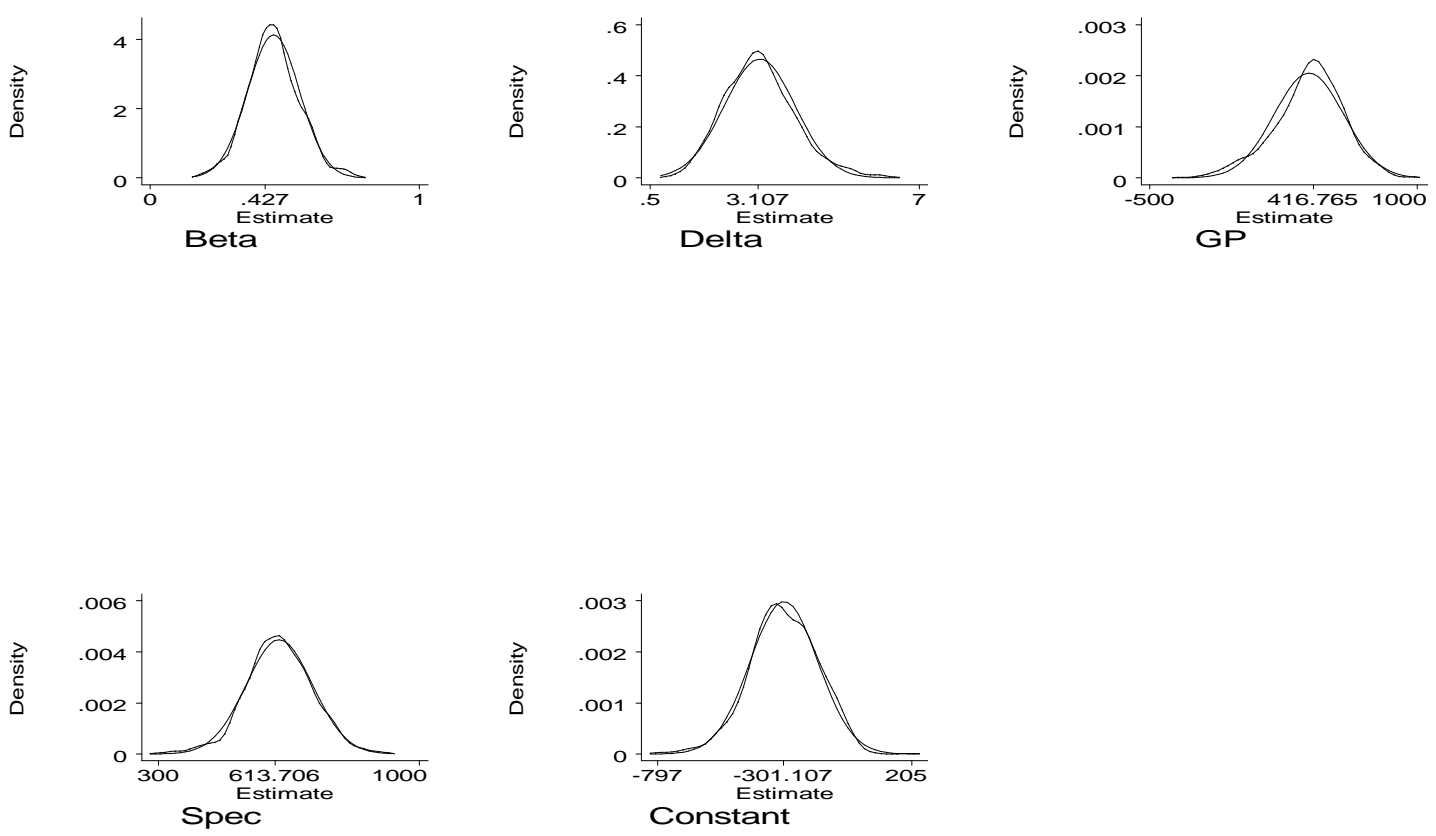

Figure 1: NLS Estimates 
Table A1. Proportion of Health Care Expenditures Going to Major Programs (in millions of 1989 Canadian dollars)

\begin{tabular}{|c|c|c|c|c|c|c|}
\hline \multirow[b]{2}{*}{ County } & \multirow[b]{2}{*}{$\begin{array}{l}\text { Current } \\
\text { Expend. }\end{array}$} & \multicolumn{5}{|c|}{ Percent of Budget Spent on } \\
\hline & & Hospitals & OHIP & ODB & $\begin{array}{l}\text { TERM } \\
\text { CARE }\end{array}$ & RESIDUAL \\
\hline Algoma & 183.793 & 48.80 & 28.33 & 4.86 & 5.09 & 12.92 \\
\hline Brant & 140.929 & 45.79 & 28.58 & 8.21 & 9.13 & 8.30 \\
\hline Durham & 408.823 & 35.62 & 25.07 & 5.59 & 7.01 & 26.72 \\
\hline Elgin & 120.192 & 30.12 & 15.98 & 5.38 & 7.22 & 41.29 \\
\hline Bruce-Grey & 187.222 & 48.65 & 23.71 & 6.76 & 10.49 & 10.39 \\
\hline Halimand & 86.058 & 37.15 & 24.56 & 9.77 & 15.45 & 13.07 \\
\hline Haliburton & 132.775 & 37.13 & 24.92 & 11.36 & 14.57 & 12.01 \\
\hline Halton & 302.966 & 37.35 & 40.98 & 5.70 & 6.02 & 9.95 \\
\hline Hamilton & 916.664 & 51.15 & 26.14 & 4.43 & 4.89 & 13.39 \\
\hline Hastings & 176.313 & 39.79 & 30.97 & 8.92 & 11.59 & 8.73 \\
\hline Huron & 63.618 & 48.25 & 21.42 & 7.65 & 10.54 & 12.14 \\
\hline Kent & 129.177 & 45.12 & 25.69 & 8.67 & 10.87 & 9.65 \\
\hline Kingston & 399.687 & 43.00 & 29.05 & 3.50 & 4.18 & 20.28 \\
\hline Lambton & 160.845 & 48.97 & 29.43 & 6.18 & 7.37 & 8.04 \\
\hline Leeds & 191.422 & 32.24 & 20.55 & 7.03 & 9.81 & 30.37 \\
\hline Middlesex & 846.415 & 53.19 & 26.61 & 3.22 & 4.25 & 12.73 \\
\hline Muskoka & 93.613 & 41.47 & 25.06 & 8.92 & 10.08 & 14.47 \\
\hline Niagara & 464.406 & 42.95 & 35.26 & 7.72 & 6.08 & 7.99 \\
\hline North Bay & 151.897 & 37.67 & 21.59 & 4.31 & 6.61 & 29.82 \\
\hline Northwestern & 101.207 & 50.07 & 18.07 & 4.19 & 4.76 & 22.92 \\
\hline Ottawa-Carlton & 1119.142 & 50.40 & 31.58 & 4.02 & 5.76 & 8.24 \\
\hline Oxford & 95.614 & 46.77 & 23.90 & 7.79 & 11.66 & 9.88 \\
\hline Peel & 574.257 & 41.49 & 40.78 & 4.68 & 5.47 & 7.58 \\
\hline Perth & 86.899 & 48.63 & 27.26 & 6.24 & 9.20 & 8.68 \\
\hline Peterbourough & 175.181 & 45.13 & 32.77 & 6.82 & 7.50 & 7.79 \\
\hline Cochrane & 153.774 & 48.79 & 18.29 & 4.14 & 5.28 & 23.51 \\
\hline Renfrew & 104.170 & 47.17 & 23.42 & 8.11 & 11.50 & 9.80 \\
\hline Eastern & 191.178 & 37.50 & 25.49 & 7.72 & 15.27 & 14.02 \\
\hline Simcoe & 335.689 & 33.79 & 28.36 & 7.04 & 7.01 & 23.80 \\
\hline Sudbury & 302.967 & 46.85 & 27.07 & 4.82 & 6.74 & 14.52 \\
\hline Thunderbay & 263.288 & 47.31 & 22.47 & 3.78 & 3.83 & 22.62 \\
\hline Timiskaming & 54.200 & 49.41 & 17.76 & 6.95 & 11.55 & 14.33 \\
\hline Waterloo & 397.489 & 44.87 & 35.09 & 5.38 & 6.68 & 7.99 \\
\hline Wellington & 226.450 & 45.46 & 29.80 & 5.66 & 9.35 & 9.73 \\
\hline Windsor & 431.119 & 45.00 & 33.06 & 6.95 & 7.47 & 7.51 \\
\hline York Region & 396.155 & 32.85 & 45.35 & 5.15 & 6.17 & 10.49 \\
\hline Metro Toronto & 4590.338 & 48.37 & 34.22 & 4.27 & 3.43 & 9.72 \\
\hline
\end{tabular}


Table A2. 1991 County Level Population and Physician Statistics

\begin{tabular}{|c|c|c|c|c|c|c|}
\hline \multirow[b]{2}{*}{ County } & \multirow[b]{2}{*}{ Population } & \multicolumn{3}{|c|}{ As a Percent of County Population } & \multicolumn{2}{|c|}{ Number of } \\
\hline & & $<5$ & 15 - 44 Female & $65+$ & GPs & SPECs \\
\hline Algoma & 127,265 & 6.81 & 21.11 & 11.10 & 96 & 70 \\
\hline Brant & 110,825 & 7.31 & 20.88 & 13.81 & 78 & 66 \\
\hline Durham & 409,095 & 8.74 & 23.56 & 8.15 & 246 & 166 \\
\hline Elgin & 75,415 & 7.49 & 20.53 & 13.94 & 49 & 37 \\
\hline Bruce-Grey & 149,300 & 6.88 & 20.08 & 15.49 & 124 & 50 \\
\hline Halimand & 98,680 & 7.26 & 21.06 & 13.25 & 58 & 15 \\
\hline Haliburton & 155,955 & 6.89 & 20.21 & 16.42 & 104 & 36 \\
\hline Halton & 313,130 & 7.06 & 22.81 & 9.63 & 329 & 234 \\
\hline Hamilton & 451,675 & 6.87 & 21.50 & 13.39 & 429 & 649 \\
\hline Hastings & 140,215 & 6.69 & 20.49 & 15.17 & 133 & 75 \\
\hline Huron & 59,080 & 7.18 & 19.31 & 16.51 & 48 & 12 \\
\hline Kent & 109,925 & 6.96 & 20.63 & 13.80 & 70 & 38 \\
\hline Kingston & 166,355 & 6.59 & 22.09 & 12.89 & 209 & 298 \\
\hline Lambton & 128,936 & 7.22 & 20.86 & 12.74 & 79 & 72 \\
\hline Leeds & 145,060 & 6.99 & 21.11 & 15.19 & 125 & 57 \\
\hline Middlesex & 372,280 & 7.22 & 21.64 & 11.88 & 395 & 656 \\
\hline Muskoka & 86,465 & 6.33 & 20.28 & 16.57 & 77 & 28 \\
\hline Niagara & 393,940 & 6.67 & 20.57 & 14.64 & 300 & 231 \\
\hline North Bay & 84,735 & 6.92 & 20.87 & 11.93 & 75 & 56 \\
\hline Northwestern & 81,736 & 8.51 & 20.89 & 10.82 & 82 & 14 \\
\hline Ottawa-Carlton & 678,150 & 6.80 & 23.63 & 10.45 & 766 & 1119 \\
\hline Oxford & 92,890 & 7.39 & 20.55 & 13.96 & 59 & 29 \\
\hline Peel & 732,795 & 7.86 & 24.21 & 6.36 & 486 & 317 \\
\hline Perth & 69,961 & 7.48 & 20.41 & 14.32 & 61 & 32 \\
\hline Peterbourough & 119,995 & 6.90 & 19.77 & 16.00 & 155 & 104 \\
\hline Cochrane & 93,925 & 7.65 & 21.97 & 9.48 & 84 & 24 \\
\hline Renfrew & 91,820 & 6.93 & 21.08 & 14.31 & 77 & 25 \\
\hline Eastern & 175,005 & 7.51 & 21.85 & 12.93 & 111 & 61 \\
\hline Simcoe & 288,680 & 7.81 & 21.87 & 12.86 & 242 & 128 \\
\hline Sudbury & 198,570 & 6.40 & 21.28 & 10.74 & 144 & 145 \\
\hline Thunderbay & 158,825 & 6.88 & 22.22 & 11.88 & 115 & 99 \\
\hline Timiskaming & 38,990 & 6.78 & 20.24 & 14.09 & 42 & 6 \\
\hline Waterloo & 377,495 & 7.63 & 22.36 & 10.16 & 279 & 228 \\
\hline Wellington & 199,505 & 7.77 & 22.01 & 11.02 & 165 & 107 \\
\hline Windsor & 327,370 & 6.87 & 20.95 & 12.83 & 225 & 230 \\
\hline York Region & 504,990 & 8.09 & 23.05 & 7.04 & 424 & 295 \\
\hline Metro Toronto & $2,276,355$ & 6.05 & 22.87 & 12.81 & 2723 & 3458 \\
\hline
\end{tabular}


Table A2. 1991 County Level Population and Physician Statistics

\begin{tabular}{|c|c|c|c|c|c|c|}
\hline \multirow[b]{2}{*}{ County } & \multirow[b]{2}{*}{ Population } & \multicolumn{3}{|c|}{ As a Percent of County Population } & \multicolumn{2}{|c|}{ Number of } \\
\hline & & $<5$ & 15 - 44 Female & $65+$ & GPs & SPECs \\
\hline Algoma & 127,265 & 6.81 & 21.11 & 11.10 & 96 & 70 \\
\hline Brant & 110,825 & 7.31 & 20.88 & 13.81 & 78 & 66 \\
\hline Durham & 409,095 & 8.74 & 23.56 & 8.15 & 246 & 166 \\
\hline Elgin & 75,415 & 7.49 & 20.53 & 13.94 & 49 & 37 \\
\hline Bruce-Grey & 149,300 & 6.88 & 20.08 & 15.49 & 124 & 50 \\
\hline Halimand & 98,680 & 7.26 & 21.06 & 13.25 & 58 & 15 \\
\hline Haliburton & 155,955 & 6.89 & 20.21 & 16.42 & 104 & 36 \\
\hline Halton & 313,130 & 7.06 & 22.81 & 9.63 & 329 & 234 \\
\hline Hamilton & 451,675 & 6.87 & 21.50 & 13.39 & 429 & 649 \\
\hline Hastings & 140,215 & 6.69 & 20.49 & 15.17 & 133 & 75 \\
\hline Huron & 59,080 & 7.18 & 19.31 & 16.51 & 48 & 12 \\
\hline Kent & 109,925 & 6.96 & 20.63 & 13.80 & 70 & 38 \\
\hline Kingston & 166,355 & 6.59 & 22.09 & 12.89 & 209 & 298 \\
\hline Lambton & 128,936 & 7.22 & 20.86 & 12.74 & 79 & 72 \\
\hline Leeds & 145,060 & 6.99 & 21.11 & 15.19 & 125 & 57 \\
\hline Middlesex & 372,280 & 7.22 & 21.64 & 11.88 & 395 & 656 \\
\hline Muskoka & 86,465 & 6.33 & 20.28 & 16.57 & 77 & 28 \\
\hline Niagara & 393,940 & 6.67 & 20.57 & 14.64 & 300 & 231 \\
\hline North Bay & 84,735 & 6.92 & 20.87 & 11.93 & 75 & 56 \\
\hline Northwestern & 81,736 & 8.51 & 20.89 & 10.82 & 82 & 14 \\
\hline Ottawa-Carlton & 678,150 & 6.80 & 23.63 & 10.45 & 766 & 1119 \\
\hline Oxford & 92,890 & 7.39 & 20.55 & 13.96 & 59 & 29 \\
\hline Peel & 732,795 & 7.86 & 24.21 & 6.36 & 486 & 317 \\
\hline Perth & 69,961 & 7.48 & 20.41 & 14.32 & 61 & 32 \\
\hline Peterbourough & 119,995 & 6.90 & 19.77 & 16.00 & 155 & 104 \\
\hline Cochrane & 93,925 & 7.65 & 21.97 & 9.48 & 84 & 24 \\
\hline Renfrew & 91,820 & 6.93 & 21.08 & 14.31 & 77 & 25 \\
\hline Eastern & 175,005 & 7.51 & 21.85 & 12.93 & 111 & 61 \\
\hline Simcoe & 288,680 & 7.81 & 21.87 & 12.86 & 242 & 128 \\
\hline Sudbury & 198,570 & 6.40 & 21.28 & 10.74 & 144 & 145 \\
\hline Thunderbay & 158,825 & 6.88 & 22.22 & 11.88 & 115 & 99 \\
\hline Timiskaming & 38,990 & 6.78 & 20.24 & 14.09 & 42 & 6 \\
\hline Waterloo & 377,495 & 7.63 & 22.36 & 10.16 & 279 & 228 \\
\hline Wellington & 199,505 & 7.77 & 22.01 & 11.02 & 165 & 107 \\
\hline Windsor & 327,370 & 6.87 & 20.95 & 12.83 & 225 & 230 \\
\hline York Region & 504,990 & 8.09 & 23.05 & 7.04 & 424 & 295 \\
\hline Metro Toronto & $2,276,355$ & 6.05 & 22.87 & 12.81 & 2723 & 3458 \\
\hline
\end{tabular}


Table A2. 1991 County Level Population and Physician Statistics 
Table A3. Per Capita OHIP and Hospital

Exenditures by Age and Gender in 1991

\begin{tabular}{|r|rr|rr|}
\hline Age Group & \multicolumn{2}{|c|}{ OHIP } & \multicolumn{2}{c|}{ Hospitals } \\
\hline & male & female & male & female \\
\hline$<5$ & 427.63 & 379.93 & 790.45 & 650.55 \\
$5-9$ & 252.54 & 234.58 & 151.29 & 124.40 \\
$10-14$ & 219.42 & 218.03 & 142.03 & 134.79 \\
$15-24$ & 251.89 & 470.88 & 217.82 & 421.36 \\
$25-34$ & 311.31 & 683.66 & 252.75 & 669.29 \\
$35-44$ & 376.75 & 639.36 & 323.40 & 462.19 \\
$45-54$ & 494.75 & 706.52 & 569.92 & 560.17 \\
$55-64$ & 677.68 & 735.65 & 1176.35 & 911.40 \\
$65-74$ & 961.68 & 893.37 & 2282.96 & 1691.12 \\
$75+$ & 1256.50 & 1129.87 & 4442.09 & 3684.67 \\
\hline
\end{tabular}


Table A4. County Level SMRs and Selected Health Status Indicies

\begin{tabular}{|c|c|c|c|c|c|c|c|c|}
\hline County & SMR_75 & SMR_65 & SAHS & HUI & PAIN & SAT & MEM & SEE \\
\hline Algoma & 1.118 & 1.151 & 1.110 & 0.996 & 0.929 & 0.964 & 0.829 & 1.038 \\
\hline Brant & 1.094 & 1.087 & 0.705 & 1.006 & 0.967 & 0.963 & 1.088 & 1.020 \\
\hline Durham & 0.927 & 0.846 & 1.095 & 0.993 & 1.125 & 1.122 & 1.104 & 1.004 \\
\hline Elgin & 0.964 & 0.942 & 0.544 & 1.001 & 1.183 & 0.999 & 0.913 & 1.003 \\
\hline Bruce-Grey & 0.987 & 0.989 & 1.016 & 1.012 & 0.736 & 0.857 & 0.933 & 1.013 \\
\hline Halimand & 1.026 & 1.042 & 1.019 & 0.995 & 0.988 & 0.801 & 1.095 & 1.057 \\
\hline Haliburton & 0.893 & 0.932 & 0.721 & 1.023 & 1.014 & 1.020 & 0.656 & 1.037 \\
\hline Halton & 0.770 & 0.709 & 1.085 & 1.037 & 0.586 & 0.927 & 0.588 & 0.933 \\
\hline Hamilton & 1.004 & 1.029 & 1.075 & 1.002 & 1.341 & 1.210 & 0.699 & 1.000 \\
\hline Hastings & 1.096 & 1.113 & 0.884 & 1.000 & 0.984 & 0.922 & 1.173 & 1.009 \\
\hline Huron & 0.860 & 0.930 & 0.715 & 1.010 & 0.724 & 0.725 & 0.926 & 1.044 \\
\hline Kent & 1.140 & 1.084 & 0.896 & 0.996 & 1.066 & 0.977 & 1.194 & 1.114 \\
\hline Kingston & 1.044 & 1.071 & 0.371 & 0.998 & 0.879 & 0.937 & 0.909 & 0.969 \\
\hline Lambton & 0.941 & 0.886 & 1.027 & 1.018 & 0.745 & 0.923 & 0.804 & 1.114 \\
\hline Leeds & 1.008 & 1.066 & 0.871 & 0.997 & 0.870 & 0.860 & 0.949 & 0.917 \\
\hline Middlesex & 0.994 & 0.979 & 0.743 & 1.000 & 1.141 & 0.982 & 0.785 & 1.000 \\
\hline Muskoka & 0.960 & 1.013 & 1.138 & 0.993 & 1.050 & 1.094 & 1.284 & 0.948 \\
\hline Niagara & 0.976 & 0.956 & 0.980 & 0.991 & 1.108 & 1.121 & 1.300 & 0.980 \\
\hline North Bay & 1.151 & 1.140 & 1.745 & 0.979 & 1.385 & 1.268 & 1.104 & 1.001 \\
\hline Northwestern & 1.237 & 1.379 & 1.236 & 0.992 & 1.059 & 1.102 & 1.162 & 0.932 \\
\hline Ottawa-Carlton & 0.899 & 0.887 & 0.797 & 0.983 & 0.754 & 0.878 & 1.149 & 1.004 \\
\hline Oxford & 0.936 & 0.910 & 0.935 & 1.003 & 0.813 & 0.898 & 0.810 & 0.938 \\
\hline Peel & 0.801 & 0.712 & 1.055 & 1.006 & 0.929 & 1.143 & 0.877 & 0.934 \\
\hline Perth & 0.861 & 0.872 & 0.955 & 1.017 & 0.982 & 0.674 & 1.016 & 1.013 \\
\hline Peterbourough & 0.941 & 0.962 & 0.753 & 0.997 & 0.886 & 0.986 & 1.150 & 0.959 \\
\hline Cochrane & 1.259 & 1.227 & 1.192 & 0.971 & 1.416 & 1.267 & 1.263 & 1.099 \\
\hline Renfrew & 1.043 & 1.051 & 1.851 & 0.998 & 1.144 & 0.929 & 1.008 & 0.974 \\
\hline Eastern & 1.086 & 1.111 & 0.605 & 1.007 & 1.016 & 1.105 & 1.243 & 0.970 \\
\hline Simcoe & 1.011 & 0.989 & 1.292 & 1.008 & 0.952 & 1.061 & 0.753 & 0.961 \\
\hline Sudbury & 1.152 & 1.198 & 1.478 & 0.964 & 1.339 & 1.326 & 1.284 & 1.081 \\
\hline Thunderbay & 1.093 & 1.158 & 1.119 & 0.989 & 1.043 & 1.116 & 1.074 & 1.021 \\
\hline Timiskaming & 1.203 & 1.212 & 1.278 & 0.979 & 1.218 & 0.945 & 1.151 & 0.977 \\
\hline Waterloo & 0.886 & 0.825 & 0.820 & 0.990 & 0.977 & 0.937 & 1.088 & 1.054 \\
\hline Wellington & 0.914 & 0.916 & 0.940 & 0.993 & 1.044 & 0.956 & 1.171 & 1.070 \\
\hline Windsor & 1.049 & 1.022 & 1.104 & 1.019 & 0.929 & 0.999 & 1.149 & 0.909 \\
\hline York Region & 0.759 & 0.652 & 0.605 & 1.020 & 0.686 & 0.768 & 0.655 & 0.924 \\
\hline Metro Toronto & 0.917 & 0.956 & 1.244 & 1.018 & 0.993 & 1.240 & 0.666 & 0.976 \\
\hline
\end{tabular}

All health status measures are restricted to individuals between ages 15 and 74 . 
Table 1. Health Care Expenditures in Ontario under Selected Funding Allocation Mechanisms Relative to an Age-Gender Adjusted Allocation (in millions of 1989 Canadian dollars)

\begin{tabular}{|c|c|c|c|c|c|}
\hline \multirow[b]{2}{*}{ County } & \multirow[b]{2}{*}{$\begin{array}{l}\text { AG Adjusted } \\
\text { Expenditures }\end{array}$} & \multicolumn{4}{|c|}{ Percent Change under } \\
\hline & & $\begin{array}{r}\text { PC } \\
\text { Adjusted }\end{array}$ & $\begin{array}{r}\text { SMR } \\
\text { Adjusted }\end{array}$ & $\begin{array}{r}\operatorname{SMR}^{\wedge}(1 / 2) \\
\text { Adjusted }\end{array}$ & $\begin{array}{r}\text { SMR^2 } \\
\text { Adjusted }\end{array}$ \\
\hline Algoma & 182.385 & 2.09 & 17.77 & 8.68 & 37.10 \\
\hline Brant & 170.981 & -5.17 & 15.23 & 7.50 & 31.25 \\
\hline Durham & 533.351 & 12.22 & -2.43 & -1.08 & -5.90 \\
\hline Elgin & 116.788 & -5.52 & 1.55 & 0.92 & 1.92 \\
\hline Bruce-Grey & 241.694 & -9.62 & 3.97 & 2.12 & 6.86 \\
\hline Halimand & 149.991 & -3.74 & 8.08 & 4.11 & 15.46 \\
\hline Haliburton & 258.161 & -11.61 & -5.97 & -2.89 & -12.60 \\
\hline Halton & 431.627 & 6.14 & -18.94 & -9.84 & -35.05 \\
\hline Hamilton & 691.542 & -4.44 & 5.71 & 2.97 & 10.46 \\
\hline Hastings & 225.038 & -8.84 & 15.42 & 7.59 & 31.69 \\
\hline Huron & 97.607 & -11.44 & -9.46 & -4.71 & -18.96 \\
\hline Kent & 169.163 & -4.93 & 20.04 & 9.72 & 42.43 \\
\hline Kingston & 250.701 & -2.91 & 9.92 & 4.99 & 19.42 \\
\hline Lambton & 192.625 & -2.07 & -0.88 & -0.29 & -2.88 \\
\hline Leeds & 233.989 & -9.30 & 6.16 & 3.19 & 11.41 \\
\hline Middlesex & 545.811 & -0.21 & 4.72 & 2.48 & 8.40 \\
\hline Muskoka & 144.285 & -12.32 & 1.06 & 0.67 & 0.94 \\
\hline Niagara & 623.614 & -7.58 & 2.75 & 1.51 & 4.36 \\
\hline North Bay & 124.697 & -0.58 & 21.23 & 10.26 & 45.26 \\
\hline Northwestern & 114.820 & 4.15 & 30.25 & 14.29 & 67.68 \\
\hline Ottawa-Carlton & 955.893 & 3.80 & -5.29 & -2.54 & -11.34 \\
\hline Oxford & 144.102 & -5.69 & -1.44 & -0.58 & -3.98 \\
\hline Peel & 901.752 & 18.90 & -15.66 & -8.03 & -29.70 \\
\hline Perth & 109.473 & -6.50 & -9.34 & -4.65 & -18.76 \\
\hline Peterbourough & 196.429 & -10.62 & -0.87 & -0.29 & -2.87 \\
\hline Cochrane & 127.385 & 7.88 & 32.54 & 15.29 & 73.65 \\
\hline Renfrew & 143.696 & -6.51 & 9.88 & 4.98 & 19.34 \\
\hline Eastern & 264.329 & -3.13 & 14.34 & 7.09 & 29.23 \\
\hline Simcoe & 432.976 & -2.45 & 6.44 & 3.32 & 11.98 \\
\hline Sudbury & 280.495 & 3.58 & 21.27 & 10.28 & 45.37 \\
\hline Thunderbay & 231.389 & 0.43 & 15.10 & 7.44 & 30.94 \\
\hline Timiskaming & 60.982 & -6.45 & 26.73 & 12.74 & 58.74 \\
\hline Waterloo & 522.741 & 5.66 & -6.70 & -3.27 & -13.95 \\
\hline Wellington & 284.965 & 2.43 & -3.79 & -1.77 & -8.50 \\
\hline Windsor & 491.699 & -2.59 & 10.51 & 5.28 & 20.72 \\
\hline York Region & 637.501 & 15.90 & -20.04 & -10.45 & -36.81 \\
\hline Metro Toronto & 3471.255 & -4.05 & -3.42 & -1.58 & -7.79 \\
\hline
\end{tabular}


Table 2. Estimates for Non-Linear SMR Adjusted Funding Model

\begin{tabular}{|c|c|c|c|c|}
\hline & \multicolumn{2}{|c|}{ NLS Estimates } & \multicolumn{2}{|c|}{ IV Estimates } \\
\hline & SMR $<75$ & SMR $<65$ & SMR $<75$ & SMR $<65$ \\
\hline \multirow[t]{2}{*}{ Beta } & 0.427 & 0.518 & 0.362 & 0.668 \\
\hline & $(5.169)$ & (5.608) & (1.365) & (2.617) \\
\hline \multirow[t]{2}{*}{ Delta } & 3.107 & 1.974 & 3.900 & 1.785 \\
\hline & $(10.510)$ & $(7.400)$ & (6.079) & (5.968) \\
\hline \multirow[t]{2}{*}{$G P$ * $(1000)$} & 416.765 & 270.832 & 547.450 & 132.534 \\
\hline & $(1.347)$ & (0.998) & $(1.445)$ & $(0.359)$ \\
\hline \multirow[t]{2}{*}{ SPEC * (1000) } & 613.706 & 581.239 & 593.900 & 575.873 \\
\hline & (2.832) & (2.839) & $(6.220)$ & (6.092) \\
\hline \multirow[t]{2}{*}{ Constant * $(100000)$} & -301.107 & -223.076 & -275.320 & -323.925 \\
\hline & $(1.035)$ & $(0.982)$ & $(1.176)$ & (1.583) \\
\hline$F(2,30)$ for $D W H$ & & & 0.71 & 0.22 \\
\hline
\end{tabular}

Absolute value of t-statistics in parentheses. The t-statistics are heteroskedastic constitent for the NLS estimates. 
Table 3. Health Care Expenditures in Ontario under Non-Linear SMR Adjusted Funding Allocation Mechanisms (in millions of 1989 Canadian dollars)

\begin{tabular}{|c|c|c|c|}
\hline \multirow{2}{*}{ County } & \multirow{2}{*}{$\begin{array}{l}\text { AG Adjusted } \\
\text { Expenditures }\end{array}$} & \multicolumn{2}{|c|}{ Percent Change under } \\
\hline & & SMR $<75$ & SMR $<65$ \\
\hline Algoma & 182.385 & 60.01 & 44.81 \\
\hline Brant & 170.981 & 49.53 & 29.33 \\
\hline Durham & 533.351 & -10.82 & -21.13 \\
\hline Elgin & 116.788 & 0.96 & -2.50 \\
\hline Bruce-Grey & 241.694 & 8.65 & 7.38 \\
\hline Halimand & 149.991 & 22.54 & 19.15 \\
\hline Haliburton & 258.161 & -20.49 & -4.53 \\
\hline Halton & 431.627 & -49.86 & -44.33 \\
\hline Hamilton & 691.542 & 14.40 & 16.08 \\
\hline Hastings & 225.038 & 50.31 & 35.64 \\
\hline Huron & 97.607 & -29.30 & -4.93 \\
\hline Kent & 169.163 & 69.78 & 28.74 \\
\hline Kingston & 250.701 & 29.12 & 25.72 \\
\hline Lambton & 192.625 & -6.33 & -13.54 \\
\hline Leeds & 233.989 & 15.92 & 24.57 \\
\hline Middlesex & 545.811 & 11.09 & 5.20 \\
\hline Muskoka & 144.285 & -0.54 & 12.56 \\
\hline Niagara & 623.614 & 4.73 & 0.40 \\
\hline North Bay & 124.697 & 75.04 & 42.15 \\
\hline Northwestern & 114.820 & 118.77 & 106.95 \\
\hline Ottawa-Carlton & 955.893 & -18.69 & -13.45 \\
\hline Oxford & 144.102 & -7.98 & -8.88 \\
\hline Peel & 901.752 & -43.30 & -43.87 \\
\hline Perth & 109.473 & -29.01 & -16.32 \\
\hline Peterbourough & 196.429 & -6.33 & 1.73 \\
\hline Cochrane & 127.385 & 130.98 & 64.40 \\
\hline Renfrew & 143.696 & 28.99 & 21.07 \\
\hline Eastern & 264.329 & 45.97 & 35.13 \\
\hline Simcoe & 432.976 & 16.84 & 7.48 \\
\hline Sudbury & 280.495 & 75.26 & 56.80 \\
\hline Thunderbay & 231.389 & 48.99 & 46.65 \\
\hline Timiskaming & 60.982 & 100.92 & 60.35 \\
\hline Waterloo & 522.741 & -22.39 & -24.86 \\
\hline Wellington & 284.965 & -14.62 & -7.66 \\
\hline Windsor & 491.699 & 31.32 & 14.53 \\
\hline York Region & 637.501 & -51.95 & -52.87 \\
\hline Metro Toronto & 3471.255 & -13.59 & 0.35 \\
\hline
\end{tabular}


Table 4. Correlation of Need and SMR Measures from the 1990 Ontario Heath Survey

Measures Excluding People over age 74

\begin{tabular}{l|rrrrrrr|}
\multicolumn{1}{l}{} & SAHS & HUI & PAIN & SAT & MEM & SEE & SMR \\
\cline { 2 - 7 } & & & & & & \\
SAHS & 1.000 & & & & & & \\
HUI & -0.332 & 1.000 & & & & & \\
PAIN & 0.450 & -0.668 & 1.000 & & & & \\
SAT & 0.449 & -0.443 & 0.685 & 1.000 & & & \\
MEM & 0.155 & -0.694 & 0.422 & 0.219 & 1.000 & & \\
SEE & 0.017 & -0.315 & 0.284 & 0.057 & 0.223 & 1.000 & \\
SMR & 0.365 & -0.632 & 0.627 & 0.432 & 0.537 & 0.245 & 1.000 \\
\hline
\end{tabular}

Measures Excluding People over age 64

\begin{tabular}{|c|c|c|c|c|c|c|c|}
\hline & SAHS & HUI & PAIN & SAT & MEM & SEE & SMR \\
\hline SAHS & 1.000 & & & & & & \\
\hline HUI & -0.313 & 1.000 & & & & & \\
\hline PAIN & 0.405 & -0.669 & 1.000 & & & & \\
\hline SAT & 0.387 & -0.438 & 0.675 & 1.000 & & & \\
\hline MEM & 0.166 & -0.694 & 0.400 & 0.196 & 1.000 & & \\
\hline SEE & 0.086 & -0.300 & 0.207 & 0.068 & 0.218 & 1.000 & \\
\hline SMR & 0.345 & -0.568 & 0.512 & 0.324 & 0.496 & 0.193 & 1.000 \\
\hline
\end{tabular}


Table 5. Health Care Expenditures in Ontario under Selected Health Status Based Funding Allocation Mechanisms (in millions of 1989 Canadian dollars)

\begin{tabular}{|c|c|c|c|c|c|c|c|}
\hline \multirow{2}{*}{ County } & \multirow{2}{*}{$\begin{array}{l}\text { AG Adjusted } \\
\text { Expenditures }\end{array}$} & \multicolumn{6}{|c|}{ Percent Change under } \\
\hline & & SAHS & HUI & PAIN & SAT & MEM & SEE \\
\hline Algoma & 182.385 & 8.04 & -5.85 & -10.52 & -20.57 & 2.11 & 5.74 \\
\hline Brant & 170.981 & -31.09 & -4.59 & -4.21 & -20.78 & -11.95 & 3.67 \\
\hline Durham & 533.351 & 6.62 & -11.74 & 24.37 & 9.50 & -12.65 & 1.91 \\
\hline Elgin & 116.788 & -46.69 & -0.59 & 35.71 & -14.39 & -3.11 & 1.83 \\
\hline Bruce-Grey & 241.694 & -1.04 & 4.58 & -40.18 & -38.08 & -4.27 & 2.96 \\
\hline Halimand & 149.991 & -0.75 & -8.76 & -0.62 & -46.47 & -12.23 & 8.01 \\
\hline Haliburton & 258.161 & -29.52 & 16.28 & 3.95 & -10.39 & 15.98 & 5.71 \\
\hline Halton & 431.627 & 5.59 & 23.01 & -59.61 & -26.97 & 23.09 & -6.19 \\
\hline Hamilton & 691.542 & 4.66 & 2.70 & 68.36 & 28.61 & 12.04 & 1.40 \\
\hline Hastings & 225.038 & -13.80 & -3.70 & -1.30 & -27.70 & -15.45 & 2.52 \\
\hline Huron & 97.607 & -30.15 & 0.83 & -41.81 & -56.70 & -3.83 & 6.47 \\
\hline Kent & 169.163 & -12.56 & -13.83 & 13.30 & -18.34 & -16.26 & 14.54 \\
\hline Kingston & 250.701 & -63.50 & -0.96 & -18.76 & -25.25 & -2.86 & -2.03 \\
\hline Lambton & 192.625 & 0.03 & 3.21 & -38.94 & -27.61 & 3.82 & 14.46 \\
\hline Leeds & 233.989 & -15.04 & 1.24 & -20.18 & -37.76 & -5.12 & -7.93 \\
\hline Middlesex & 545.811 & -27.38 & -2.48 & 27.40 & -17.48 & 5.22 & 1.42 \\
\hline Muskoka & 144.285 & 10.78 & -7.02 & 10.39 & 3.80 & -19.53 & -4.41 \\
\hline Niagara & 623.614 & -4.46 & -8.69 & 21.16 & 9.48 & -20.04 & -0.79 \\
\hline North Bay & 124.697 & 69.15 & -14.65 & 77.95 & 42.11 & -12.64 & 1.57 \\
\hline Northwestern & 114.820 & 20.21 & -7.52 & 12.06 & 5.47 & -15.01 & -6.22 \\
\hline Ottawa-Carlton & 955.893 & -22.19 & -12.08 & -37.56 & -34.90 & -14.52 & 1.91 \\
\hline Oxford & 144.102 & -8.80 & 1.21 & -28.88 & -31.77 & 3.43 & -5.56 \\
\hline Peel & 901.752 & 2.72 & 1.86 & -10.56 & 14.01 & -0.96 & -6.02 \\
\hline Perth & 109.473 & -6.89 & 6.65 & -1.65 & -62.86 & -8.56 & 2.98 \\
\hline Peterbourough & 196.429 & -26.41 & -7.28 & -17.54 & -16.66 & -14.53 & -3.17 \\
\hline Cochrane & 127.385 & 15.91 & -20.65 & 84.93 & 41.84 & -18.79 & 12.78 \\
\hline Renfrew & 143.696 & 79.25 & -1.38 & 28.02 & -26.63 & -8.19 & -1.51 \\
\hline Eastern & 264.329 & -40.77 & 2.53 & 4.27 & 6.17 & -18.08 & -1.94 \\
\hline Simcoe & 432.976 & 25.60 & 7.06 & -6.77 & -2.75 & 7.59 & -2.92 \\
\hline Sudbury & 280.495 & 43.42 & -23.31 & 67.90 & 56.34 & -19.51 & 10.70 \\
\hline Thunderbay & 231.389 & 8.90 & -18.50 & 9.15 & 8.35 & -11.31 & 3.79 \\
\hline Timiskaming & 60.982 & 24.23 & -10.76 & 42.56 & -23.94 & -14.57 & -1.15 \\
\hline Waterloo & 522.741 & -19.93 & -19.68 & -2.44 & -25.31 & -11.91 & 7.57 \\
\hline Wellington & 284.965 & -8.34 & -14.77 & 9.33 & -21.95 & -15.39 & 9.44 \\
\hline Windsor & 491.699 & 7.49 & 10.73 & -10.64 & -14.34 & -14.52 & -8.83 \\
\hline York Region & 637.501 & -40.73 & 13.51 & -47.00 & -50.96 & 16.06 & -7.13 \\
\hline Metro Toronto & 3471.255 & 20.90 & 7.74 & 0.36 & 35.56 & 15.08 & -1.24 \\
\hline \multicolumn{8}{|c|}{ Parameter Estimates } \\
\hline \multirow{2}{*}{\multicolumn{2}{|c|}{ Beta }} & 0.443 & 0.478 & 0.312 & 0.374 & 0.598 & 0.374 \\
\hline & & $(4.937)$ & (3.536) & (2.530) & $(4.640)$ & (3.488) & (3.534) \\
\hline \multirow{2}{*}{\multicolumn{2}{|c|}{ Delta }} & 0.990 & 3.755 & 1.724 & 2.123 & -0.544 & 1.122 \\
\hline & & (3.159) & $(4.090)$ & (2.354) & (6.352) & $(1.377)$ & $(0.919)$ \\
\hline
\end{tabular}

All measures restricted to individuals under the age of 75 . Absolute value of heteroscedastic consistent t-statistics in parentheses. 